
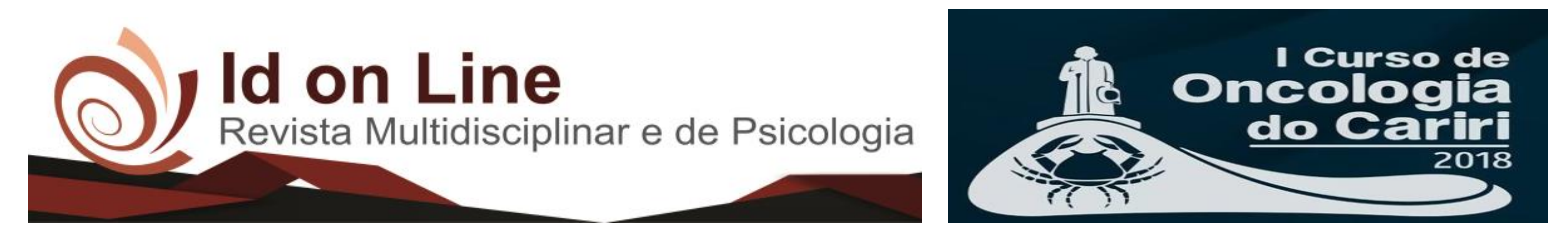

Resumo

\title{
PERSPECTIVAS DE TRATAMENTO DO CÂNCER COLORRETAL A PARTIR DA CRISINA
}

Karla Graziely Soares Gomes ${ }^{1}$; Maria Stella Batista de Freitas Neta ${ }^{1}$; Maria Eliana Pierre Martins ${ }^{2,3}$.

Introdução: A crisina é um quimioprotetor natural da classe das flavonas. Recentemente, temse intensificado os estudos desenvolvidos com essa substância e, com isso, são descobertas novas propriedades nutracêuticas que abrangem atributos terapêuticos de doenças, incluindo o câncer. Contudo, no Brasil, alguns tipos de câncer, como o câncer colorretal, não fazem parte dos programas de rotina de políticas públicas, dificultando o rastreamento, a prevenção e, portanto, o tratamento da doença, já que se apresenta, geralmente, assintomático. Objetivo: O presente estudo tem por intuito realizar uma revisão das propriedades relacionadas à crisina $\mathrm{e}$ as interpretações quando correlacionada ao câncer colorretal $\left(2^{\circ}\right.$ e $3^{\circ}$ mais comum nas mulheres e homens brasileiros, respectivamente), destacando possíveis vias de tratamento e de prevenção que contribuam para melhorar a condição de saúde e de vida de tais indivíduos. Método: Foi desenvolvida uma revisão sistemática de artigos identificados dos cinco últimos anos (2014 a 2018). Para tanto, a estratégia de busca utilizou descritores de acordo com a nomenclatura MeSH (flavonoids, cancer and colon) nas bases de dados PubMed, Medline, Scopus e Lilacs. Nessa perspectiva foram encontrados 482 artigos, dos quais apenas 9 foram incluídos na análise completa, baseados em critérios de elegibilidade temática. Resultados: Ao analisar o câncer colorretal, percebe-se que é causado por uma série de fatores de natureza dietética, genética e ambiental, sendo que grande parte se inicia a partir de pólipos, inflamação intestinal e outros contribuintes. Posto isso, nos artigos analisados, constatou-se que a crisina tem atividades antioxidantes, anti-inflamatórias, anticancerígenas e antivirais. Conjuntamente, a crisina exerce efeitos citotóxicos com a apoptose nas células CT26, demonstrando efeito anticancerígeno nas células cancerosas do cólon. Tais efeitos se estendem quando analisada em conjunto com substâncias de tratamento do câncer de cólon, como o 5-fluorouracil. Assim, crisina é uma alternativa para esse tipo de câncer, pois diminui tanto as lesões patológicas quanto o número de focos de cripta aberrantes. Conclusão: Essas descobertas introduzem a crisina como um agente terapêutico do câncer de cólon, sendo necessário o desenvolvimento de mais estudos que elucidem de forma mais aprofundada esses aspectos e outros ainda não identificados para que ela possa contribuir, de fato, para atenuar essa realidade de muitos brasileiros.

Palavras-chave: Crisina. Câncer Colorretal. Flavonas. Flavonoides. Saúde Natural.

\footnotetext{
${ }^{1}$ Graduanda da Faculdade de Medicina da UFCA;

${ }^{2}$ Doutoranda em ciências da saúde pela Faculdade de Medicina ABC paulista;

${ }^{3}$ Professora adjunta da Faculdade de Medicina da UFCA; Autor correspondente: karlagrazielysg@gmail.com.
}

32 Id on Line Rev. Mult. Psic. V.12, N. 40. 2018 - ISSN 1981-1179 EDIÇÃO ESPECIAL: I CURSO DE ONCOLOGIA DO CARIRI / II JORNADA DE PESQUISA QUANTI-QUALITATIVA EM ONCOLOGIA. JUAZEIRO DO NORTE, 05 A 10 DE MARÇO DE 2018. Edição eletrônica em http://idonline.emnuvens.com.br/id 